\title{
Obtención y caracterización de carbón activado obtenido de lodos de plantas de tratamiento de agua residual de una industria avícola
}

\section{Obtaining and Characterization of Activated Carbon Obtained Sludge Treatment Plant Wastewater from a Poultry Industry}

\author{
Rojas-Morales Jorge Luis \\ Universidad del Zulia, Venezuela \\ Facultad de Ingeniería \\ Centro de Investigación del Agua \\ Correo:postyorojas@gmail.com \\ Gutiérrez-González Edixon Cristóbal \\ Universidad del Zulia, Venezuela \\ Facultad de Ingeniería \\ Centro de Investigación del Agua \\ Correo:egutierr12@gmail.com
}

\author{
Colina-Andrade Gilberto de Jesús \\ Universidad del Zulia, Venezuela \\ Facultad de Ingeniería \\ Departamento de Ingeniería Sanitaria y Ambiental \\ Correo: gjcolinaa@gmail.com
}

Información del artículo: recibido: mayo de 2015, reevaluado: mayo de 2016, aceptado: junio de 2016

\section{Resumen}

Se evaluó la capacidad de adsorción en carbones activados, obtenidos de lodos provenientes de un matadero de aves de la localidad. El precursor se activó con $\mathrm{H}_{3} \mathrm{PO}_{4}$ a 10, 20, 30 y $35 \%$ en una relación 1:1. Se pirolizó a $450^{\circ} \mathrm{C}$ por $2 \mathrm{~h}$, en atmósfera $\mathrm{N}_{2}$ a un flujo de $50 \mathrm{~mL} / \mathrm{min}$, obteniendo los carbones $\mathrm{C}_{10}, \mathrm{C}_{20}$ $\mathrm{C}_{30} \mathrm{y} \mathrm{C}_{35}$. Se utilizó el DARCOG60 como carbón activado referencial. Se evaluó la capacidad adsortiva de los carbones activados obtenidos, utilizando la técnica del índice de azul de metileno (AM). El mejor adsorbente se caracterizó en función al contenido de humedad, cenizas, densidad aparente y $\mathrm{pH}$. Se determinó su composición elemental ( $\mathrm{CHNO})$, espectrofotometría infrarroja FTIR y microscopía electrónica de barrido SEM. El $\mathrm{C}_{35}$ obtuvo mayor adsorción de colorante $\left(88.44 \%\right.$ de remoción y $43.48 \mathrm{mg}$ de $\mathrm{AM} / \mathrm{g}$ de $\left.\mathrm{C}_{35}\right)$. El DARG60 presentó $86.43 \%$ de remoción del AM. El contenido de carbono en el carbón obtenido aumentó en relación con el lodo avícola precursor. El contenido de hidrógeno disminuyó significativamente (Lodo > Carbón). Las fotomicrografías SEM, evidenciaron la aparición de una estructura externa porosa en el Carbón a diferencia del precursor. EL FTIR reportó la aparición de varias bandas asimétricas en el Carbón, correspondientes a diferentes grupos funcionales en su superficie, evidenciando una estructura aromática además de grupos $\mathrm{OH}$.

\section{Descriptores:}

- carbón activado

- lodo

- azul de metileno

- espectrofotometría

- fotomicrografías 


\begin{abstract}
The adsorption capacity of activated carbons, obtained from poultry slaughterhouse sludge was evaluated. The precursor was activated with $\mathrm{H}_{3} \mathrm{PO}_{4} 10,20,30$ and $35 \%$ in a 1: 1 ratio and pyrolyzed at $450^{\circ} \mathrm{C}$ for $2 \mathrm{~h}$ in $N^{2}$ atmosphere at a flow of $50 \mathrm{~mL} /$ min, obtaining the $C_{10}, C_{20}, C_{30}$ and $C_{35}$ carbons. The DARCOG60 was used as referential activated carbon. The adsorptive capacity of activated carbons obtained was evaluated, using the technique of methylene blue index (AM). The best adsorbent was characterized in terms of moisture content, ash content, bulk density and $\mathrm{pH}$. Elemental composition (CHNO), infrared spectrophotometry FTIR and SEM scanning electron microscopy was determined. The C35 got higher dye adsorption ( $88.44 \%$ removal and $43.48 \mathrm{mg} \mathrm{AM} / \mathrm{g}$ of $C_{35}$ ). The DARG60 presented a $86.43 \%$ removal of AM. The carbon content in coal obtained poultry increase over the precursor slurry. The hydrogen content decreased significantly (sludge > carbon). The SEM photomicrographs, showed the appearance of a porous outer structure unlike the precursor carbon. FTIR reported the occurrence of several asymmetric carbon bands corresponding to different functional groups on their surfaces, evidencing an aromatic structure besides $\mathrm{OH}$ groups.
\end{abstract}

\section{Keywords:}

- activated carbon

- sludge

- methylene blue

- spectrophotometry

- photomicrographs

\section{Introducción}

Durante el proceso de matanza de aves el agua se utiliza principalmente para el escaldado, lavado antes y después del eviscerado, enfriamiento (chiller), limpieza y saneamiento de equipos e instalaciones, así como para el enfriamiento de equipos mecánicos. También se emplea para remover las plumas y vísceras desde las áreas de producción. Se ha reportado que el consumo específico de agua se encuentra entre 8 y $15 \mathrm{~L} /$ ave sacrificada (Caldera et al., 2010). Los lodos son el principal residuo del tratamiento de aguas residuales, por ello, la adecuada reducción de volumen, eliminación de microorganismos patógenos y virus, ya que es un requerimiento de cualquier planta de tratamiento, con la finalidad de un mínimo impacto al medio ambiente.

Prácticamente todos los materiales con un elevado contenido en carbono se pueden utilizar como materia prima para la obtención de carbón activado, el lodo de la planta de agua residual avícola tiene un gran contenido de materia orgánica. Estudios anteriores como el de Herdenez (2014) reporta valores similares, sin embargo, los carbones comerciales se producen principalmente a partir de combustibles fósiles como la antracita, el lignito, la turba o materiales como la madera. Los recursos limitados de las materias primas y su elevado costo, en conjunto con la cada vez más extensa aplicación de los carbones activados en la eliminación de contaminantes, hace necesario producir carbón activado utilizando materia prima que a la fecha no se aprovecha (Sarmiento et al., 2004), promocionando esta investigación de nuevos materiales como precursores para la obtención de materiales adsorbentes.
El uso de lodos residuales en plantas de tratamiento de aguas domiciliarias directamente como adsorbentes se ha estudiado por varios autores sin muy buenos resultados, sin embargo, se obtuvieron excelentes materiales adsorbentes al transformarlos por pirolisis en carbones (Ros, 2006).

La Agencia para la Protección Ambiental de EEUU (USEPA) recomienda el carbón activado como una de las mejores tecnologías disponibles para la remoción de contaminantes orgánicos (Mukherjee et al., 2007). La adsorción en sólidos, particularmente en carbón, ha demostrado ser muy eficaz para la remoción de metales tóxicos presentes en fase liquida (Basso et al., 1992), su principal desventaja radica en el costo del adsorbente, ya que puede ser muy alto, según (Méndez et al., 2008).

La búsqueda de una nueva vía para llevar a cabo la valoración de lodos avícolas, a través del estudio de parámetros que permitan la optimización en la preparación de carbones activados, es el fundamento de esta investigación. Así, se lograría una completa estabilización de los biosólidos, eliminando totalmente los microorganismos patógenos y se llevaría a cabo la generación de un adsorbente final. La producción de carbón activado a partir de material residual, tiene gran importancia económica y se enmarca dentro de los proyectos que de una manera u otra contribuyen a un mejor y oportuno aprovechamiento de los recursos, en particular, los de naturaleza carbonácea.

El objetivo de esta investigación fue obtener y caracterizar carbón activado a partir de lodos de un sistema de tratamiento de agua residual de una industria avícola. 


\section{Parte Experimental}

Preparación de la muestra de lodo

La muestra de lodo avícola se captó en diferentes puntos de seis lechos de secados en la planta de tratamiento de aguas residuales. La muestra se secó a una temperatura de $40 \pm 2^{\circ} \mathrm{C}$ por 24 horas, después se molió y pasó por un tamiz Núm. 10 de $2 \mathrm{~mm}$ de abertura para su caracterización fisicoquímica.

\section{Caracterización de los lodos y carbones activados}

Se tomó una alícuota de la muestra y se determinaron los siguientes parámetros de acuerdo con las técnicas de "Estándar methods for the examination of wáter and wastewater" (AWA, 1998).

- Determinación de pH

- Determinación del contenido de humedad de la muestra de lodo

- Determinación del contenido de materia orgánica

- Determinación del contenido en cenizas en lodos

La determinación del contenido en ceniza se realizó completamente automatizado en un equipo LECO AF700 por diferencia de peso entre la muestra inicial y final.

\section{Análisis elemental $\mathrm{CHN}$ de lodos y carbones}

El análisis elemental de los materiales, contenido carbono, hidrogeno y nitrógeno, se realizó por medio de un analizador elemental marca LECO TRUSPEC.

Técnica experimental de preparación del carbón activado

Los lodos previamente molidos se secaron a $105^{\circ} \mathrm{C}$ mediante estufa de laboratorio (P. Selecta modelo 209) durante 24 horas.

Para la activación química con $\mathrm{H}_{3} \mathrm{PO}_{4}$, se llevó a cabo un proceso de impregnación, que consistió en añadir $10 \mathrm{~mL}$ de una solución de $\mathrm{H}_{3} \mathrm{PO}_{4}$ al 10, 20 y 30\% en volumen, a $10 \mathrm{~g}$ de lodo seco. La solución se agitó durante 2 horas a $85^{\circ} \mathrm{C}$ y posteriormente se evaporó hasta la sequedad a $105^{\circ} \mathrm{C}$ durante 2 horas. Posteriormente, se llevó a cabo una pirolisis, donde aproximadamente $15 \mathrm{~g}$ de muestra seca se calentó en un reactor tubular de cuarzo bajo atmósfera de $\mathrm{N}_{2}(50 \mathrm{~mL} / \mathrm{min})$ con una rampa de calentamiento de $5^{\circ} \mathrm{C} \min ^{-1}$, hasta alcanzar $450^{\circ} \mathrm{C}$. Durante 2 horas las muestras se enfriaron en el horno con la misma atmósfera.

\section{Caracterización preliminar por adsorción de solu- ciones en los CLA-CDG60 y LA}

Con el objetivo de analizar el carbón con el mejor desempeño de adsorción se utilizó inicialmente una técnica de adsorción de soluciones coloreadas (índice de azul de metileno).

El índice de azul de metileno: se estima como el número de miligramos de azul de metileno decolorada por $0.1 \mathrm{~g}$ de carbón activado. Es un método rápido para conocer la capacidad de adsorción de un carbón activado frente a moléculas grandes (Giraldo et al., 2008), el proceso consistió en adicionar a $25 \mathrm{~mL}$ de una solución de azul de metileno aproximadamente de 200 mg/L de AM, 100 mg de carbón activado y someterlo a agitación durante 24 horas. Se tomó una alícuota de $1 \mathrm{~mL}$ de cada muestra, completa a $100 \mathrm{~mL}$ en una solución a 5\% de ácido acético, se filtró al vacío utilizando un filtro de acetato de $0.45 \mu \mathrm{m}$ y se estabilizó el pH a 7 (con solución de $\mathrm{NaOH}$ al $0.5 \mathrm{~N}$ ); a continuación, se midió la absorbancia en espectrofotómetro HACH DR2800 a una longitud de onda de $620 \mathrm{~nm}$ y se sacó la diferencia con la solución de partida, lo que determinó la cantidad de mg adsorbido, con base en los datos anteriores, se calcularon los mg de azul de metileno adsorbido por gramos de carbón activado. Este se realizó para lodo precursor, el CDG60 y cinco carbones preparados en laboratorio con diferentes porcentajes de $\mathrm{H}_{3} \mathrm{PO}_{4}$ en su preparación utilizaron los siguientes porcentajes de 15, 20, 25, 30, 35\% para cada carbón obtenido C15, C20, C25, C30, C35.

\section{Densidades aparentes del CLA-CDG60}

La densidad aparente de los adsorbentes se midió por los procedimientos ASTM D 2854-(2000).

\section{Determinación del pH del CLA-CDG60}

Se midió el $\mathrm{pH}$ de los adsorbentes por el procedimiento de la Norma AShTM D-3838-80.

\section{Contenido de humedad del CLA-CDG60}

El contenido de humedad por el procedimiento estándar ASTM D2867-09.

\section{Análisis elemental CHN del CLA-CDG60}

Se extrajo una alícuota y se analizó (carbono, hidrógeno, oxígeno, azufre y nitrógeno), en la unidad de análisis elemental LECO TRUSPEC completamente siste- 
matizado, similar a como se describe el procedimiento de análisis elemental de lodo.

\section{Análisis de espectroscopía de infrarrojo del CLA-CDG60}

Este análisis se realizó mediante un espectrómetro de infrarrojo (SHIMADZU modelo IRPrestige-21), la muestra de lodo avícola seco y los carbones activados CLA y CDG60 se analizaron por medio de la técnica (FT-IR). Los análisis se realizaron empleando pastilla con $\mathrm{KBr}$ siguiendo los procedimientos establecidos en la norma ASTM E-168/E-1252, este análisis se elaboró en los laboratorios de la Fundación Instituto Zuliano de Investigaciones Tecnológicas, INZIT Maracaibo.

\section{Análisis morfológico del precursor y de los carbones activados mediante microscopía electrónica de barrido (SEM)}

Para poder apreciar la morfología del precursor y de los carbones activados con mayor nitidez, se usó la técnica de suspensión y los carbones se cubrieron con una película de oro para hacer la muestra conductora, antes del análisis en un microscopio electrónico de barrido (MEB). Marca Jeol, modelo jsm 6390.

\section{Resultados y discusión}

Caracterización preliminar de adsorción de azul de metileno sobre el precursor y los carbones activados

A continuación se presentan los resultados preliminares obtenidos de los procedimientos de activación química aplicados al lodo avícola, utilizando azul de metileno (AM) como adsorbato. Este análisis preliminar permitió la selección del carbón activado con mejo- res propiedades de adsorción para su posterior caracterización y aplicación, este se acompañó de un análisis estadístico. La región de exploración para ajustar el modelo fue el porcentaje de ácido fosfórico de activación a $450^{\circ} \mathrm{C}$.

La tabla 1 presenta los resultados de la adsorción de azul de metileno (AM) del lodo avícola (LA), de carbones preparados a los porcentajes de $15 \%, 20 \%, 25 \%$, 30\%, 35\% (C15, C20, C25, C30, C35) y el CDG60, tabla 1.

Se observa, que a medida que aumentan los porcentajes de agente activante $\mathrm{H}_{3} \mathrm{PO}_{4}$ en la relación de impregnación del lodo, se incrementa la remoción de azul de metileno; similares resultados obtuvieron Paredes (2011) con carbones activados preparados a partir de cascara de castaña y Giraldo et al. (2008) con carbones preparados de concha de coco, donde sugieren un aumento de adsorción de azul de metileno con el incremento del ácido fosfórico, en la impregnación con sus respectivos precursores. Se puede inferir, que el material precursor tuvo un desarrollo de su mesoporosidad. Los mesoporos son apropiados para la adsorción de las moléculas de AM por su tamaño, debido al incremento del porcentaje de ácido fosfórico al que se sometió en su activación, lo que aumentó su capacidad de retener el azul de metileno (Paredes, 2011).

La activación del precursor es clave para aumentar la capacidad de adsorción del material lodo avícola (LA), como se puede observar en la tabla 1, el porcentaje de remoción del precursor aumenta debido al tratamiento químico y termico al que se somete con un $53.77 \%$ a valores comprendidos entre un $70.18 \%$ y $88.44 \%$. Según la evidencia experimental, se seleccionó el carbón $\mathrm{C}_{35}$ con el mejor desempeño en la adsorción de AM y se le denominó carbón de lodo activado (CLA) con el que se trabajó de aquí en adelante, realizándole su respectiva caracterización fisicoquímica.

Tabla 1. Porcentaje de remoción de AM y capacidad de adsorción de AM para el precursor $L A$ y los carbones $C_{15}, C_{20}, C_{25}, C_{30}, C_{35}$ y CDG60

\begin{tabular}{ccc}
\hline Carbón activado & \% Remoción & mg azul metileno/g carbón \\
\hline LA & $53.77 \pm 0.77^{\mathrm{F}}$ & $26.75 \pm 0.25^{\mathrm{F}}$ \\
$\mathrm{C}_{15}$ & $70.18 \pm 0.83^{\mathrm{E}}$ & $34.92 \pm 0.52^{\mathrm{E}}$ \\
$\mathrm{C}_{20}$ & $76.88 \pm 0.62^{\mathrm{D}}$ & $38.25 \pm 0.50^{\mathrm{D}}$ \\
$\mathrm{C}_{25}$ & $81.41 \pm 0.50^{\mathrm{C}}$ & $39.92 \pm 0.14^{\mathrm{C}}$ \\
$\mathrm{C}_{30}$ & $85.59 \pm 0.58^{\mathrm{B}}$ & $42.58 \pm 0.38^{\mathrm{B}}$ \\
$\mathrm{C}_{35}$ & $88.44 \pm 0.53^{\mathrm{A}}$ & $43.48 \pm 0.43^{\mathrm{A}}$ \\
$\mathrm{CDG}^{\mathrm{B} 0}$ & $86.43 \pm 0.54^{\mathrm{AB}}$ & $43.00 \pm 0.43^{\mathrm{B}}$ \\
\hline
\end{tabular}

Nota: Letras diferentes en la misma columna indican diferencia significativa según la prueba de Tukey $(p \leq 0,05)$ desviación estándar para tres replicas 


\section{Caracterización fisicoquímica del material precursor y carbones activados}

Los resultados de los análisis de las características fisicoquímicas, el carbón activado de lodos avícolas CLA, el carbón activado CDG60 y el lodo seco, se muestran en la tabla 2, donde se pueden observar la densidad aparente, contenido de humedad, contenido de cenizas, $\mathrm{pH}$ y contenido de materia orgánica.

El contenido de materia orgánica del lodo avícola (LA) fue de $67.4 \pm 0.5 \%$, similar al reportado por Herdenez (2014), quien trabajó con lodo avícola de la misma planta de tratamiento de esta investigación, cuyo porcentaje fue de $66.43 \pm 2.96 \%$. Esta característica hace de este precursor una fuente potencial para obtener material carbonoso. Según Velázquez et al. (2010), mayor cantidad de materia orgánica presente en el precursor da origen a carbones activados con mejores rendimientos. El contenido de cenizas, presente en el lodo seco fue de $24.6 \%$, este se elevó comparado con los valores reportados por Contreras (2010), quien trabajó con otros precursores, sin embargo, una vez procesado el lodo, hasta la obtención del CLA este baja significativamente a $1.9 \%$, decrece 12.89 veces frente al presentado en el material precursor. Esta reducción en el contenido de cenizas en el carbón CLA, se debe al proceso de activación al que se sometió el precursor para su posterior conversión a carbón activado. Este proceso generó porosidad en la superficie del material, lo cual produjo una estructura externa específica, como se muestra más adelante en la microscopía electrónica de barrido (SEM).

Se infiere que el proceso de pirolisis ocasionó la producción de vías de acceso a la ceniza depositada dentro del lodo, con lo cual, después de un lavado exhaustivo con abundante agua destilada, dichos minerales e impurezas, se retiraron, mejorando su eficiencia, debido a la disminución de masa dentro del carbón. La reducción de la densidad aparente del lodo precursor de $0.84 \pm 0.01$ a $0.50 \pm 0.01 \mathrm{~g} / \mathrm{mL}$, infiere que al aumentar la porosidad del material por los procesos de activación química (deshidratación) y pirolisis posterior, incrementó su área superficial específica, a la vez que el volumen ocupado por estas partículas fue mayor.

\section{Caracterización química (análisis elemental) del lodo avícola (LA), CLA y CDG60}

El resultado de este análisis carbono, hidrogeno y nitrógeno, para el precursor de lodo avícola LA, carbón activado de lodo avícola CLA y carbón comercial DarcoG60, se muestra en la tabla 3.

El contenido de carbono elemental del carbón preparado CLA se muestra elevado en comparación con el de lodo avícola LA, esto se debe fundamentalmente al proceso de carbonización del precursor mediante la pirolisis, con lo cual se infiere que se creó una estructura microcristalina muy parecida a la del grafito. Bansal et al. (1988) asegura que el carbono es el componente mayoritario de los carbones activados al estar presente entre un 85 a $95 \%$. Sin embargo, contienen otros elementos como hidrógeno, nitrógeno, sulfuro y oxígeno. Estos heteroátomos pueden provenir del material de partida o introducirse durante las etapas de preparación. Normalmente se encuentran en la superficie del carbón activado formando complejos o grupos funcionales, los

Tabla 2. Características fisicoquímicas del lodo avícola seco (LA), de los carbones CLA y CDG60

\begin{tabular}{cccccc}
\hline Material & $\begin{array}{c}\text { Densidad aparente } \\
\mathrm{g} / \mathrm{mL}\end{array}$ & $\begin{array}{c}\text { Humedad } \\
(\%)\end{array}$ & $\begin{array}{c}\text { Cenizas } \\
(\%)\end{array}$ & $\mathrm{pH}$ & $\begin{array}{c}\text { M.O. } \\
(\%)\end{array}$ \\
\hline LA & $0.838 \pm 0.01$ & $89.88 \pm 2.24$ & 24.6 & $6.76 \pm 0.25$ & $67.4 \pm 0.5$ \\
CLA & $0.499 \pm 0.01$ & $4.01 \pm 0.07$ & 1.9 & $2.52 \pm 0.12$ & - \\
CDG60 & $0.39 \pm 0.01$ & $4.26 \pm 0.08$ & 20.9 & $3.04 \pm 0.08$ & - \\
\hline
\end{tabular}

$\mathrm{MO}$ contenido de materia orgánica

Tabla 3. Análisis elemental (CHNO) de LA, CLA y CDG60

\begin{tabular}{ccccc}
\hline \multirow{2}{*}{ Muestras } & \multicolumn{4}{c}{$\begin{array}{c}\text { Porcentaje en peso, base seca libre de } \\
\text { cenizas }\end{array}$} \\
\cline { 2 - 4 } & $\mathrm{C}(\%)$ & $\mathrm{H}(\%)$ & $\mathrm{N}(\%)$ & $\mathrm{O}^{*}(\%)$ \\
\hline LA & 33.69 & 5.61 & 4.73 & 55.97 \\
CLA & 81.25 & 0.88 & 0.008 & 17.79 \\
CDG60 & 33.83 & 1.73 & $0.54 \%$ & 63.9 \\
\hline
\end{tabular}

*Estimado por diferencia basado en publicación de (Baso et al., 2001). No se detectó la presencia de azufre en las muestras analizadas (ver análisis FTIR) 
cuales le confieren a la superficie propiedad polar y característica ácido base (Paredes, 2011).

En la figura 1 se evalúan los espectros IR que comparan el lodo avícola con el carbón CLA, se realizan algunas asignaciones de número de onda a los cambios que ocurren en el precursor LA, al transformarse en un material de carbón activo.

Al evaluar los espectros IR de la figura 1 que compara el lodo avícola con el carbón CLA, albergan todas las bandas características del material precursor y carbón obtenido. Alrededor de los $3595 \mathrm{~cm}^{-1}$ en el carbón CLA, se observa la aparición de una banda con marcada intensidad (alargamiento), correspondiente al grupo hidroxilo $(\mathrm{OH})$; se infiere que es un producto de fenoles que aparecen en el carbón CLA, según la tabla espectral (Coates, 2000).

El CLA tiene una mayor presencia de grupos funcionales que el material precursor del lodo avícola, lo que lo convierte en un potencial adsorbente de diversos compuestos, además se puede observar la presencia de grupo hidrofílico como el $\mathrm{OH}$ que es bastante reactivo por su función anfótera.

En la tabla 4, se evalúan los espectros IR de la figura 1 que compara el lodo avícola con el carbón CLA. Se realizan asignaciones de número de onda a los cambios que ocurren en el precursor LA, al transformarse en un material de carbón activo.

\section{Análisis morfológico del precursor y de los carbo- nes mediante microscopía electrónica de barrido (SEM)}

En la figura 2 se muestran fotomicrografías donde se pueden comparar las estructuras externas del precursor LA, respecto al carbón activado preparado CLA.

La estructura externa del lodo avícola seco (figuras $2 a$ y $2 b$ ), presenta un aspecto de escamas apiladas de forma desordenada. La estructura se muestra compacta; pueden observarse pocos intersticios entre "escama" y "escama". Se contabilizan pocos poros grandes en el lodo a esta resolución, lo que indica que desde el punto de vista morfológico, es un material con poca porosidad, al analizar las imágenes.

Con estas imágenes, se muestra un desarrollo de la porosidad en el material precursor LA, esto se puede observar en la figura $2 b$ del LA y la figura $2 c$ del CLA, ambas tomadas con la misma resolución de 5000x. Se puede observar la cantidad de macroporos y mesoporos creados en el carbón obtenido CLA, lo que evidencia el efecto del agente activante $\left(\mathrm{H}_{3} \mathrm{PO}_{4}\right)$ en la estructura del lodo, acompañado del tratamiento de pirolisis. La activación con ácido fosfórico promueve un proceso de dilatación del material. Daouda et al. (2013) afirman que químicamente el ácido fosfórico asume un papel de agente de deshidratación durante la activa-

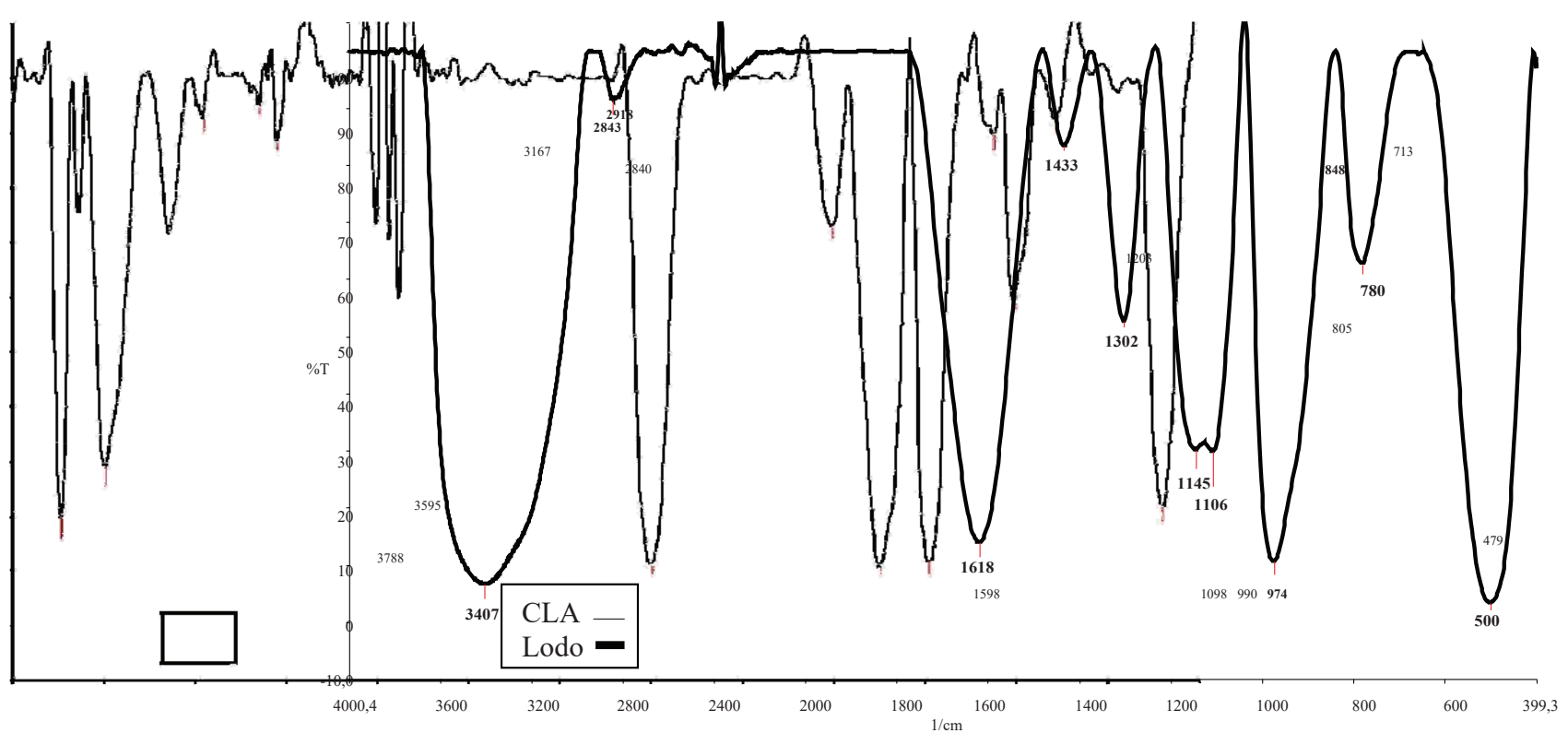

Figura 1. Comparación entre los espectros FTIR de lodo-Carbón CLA 
DOI: https://doi.org/10.1016/j.riit.2016.11.005

Rojas-Morales Jorge Luis, Gutiérrez-González Edixon Cristóbal, Colina-Andrade Gilberto de Jesús

Tabla 4. Asignaciones de los cambios, espectros IR del LODO al carbón CLA

\begin{tabular}{|c|c|c|c|}
\hline Núm. deOnda $\mathrm{cm}^{-1}$ & Asignación & Efecto & Causa posible \\
\hline 3788 & Replica banda estiramiento simétrico $\mathrm{OH}$ & Aparición & Presencia de humedad en la muestra \\
\hline 3595 & Banda estiramiento simétrico $\mathrm{OH}$ & Aparición & Fenoles \\
\hline 3407 & Banda estiramiento simétrico $\mathrm{OH}$ & Desaparece & Volumen de agua en los capilares \\
\hline 3167 & Vibración estiramiento simétrico y asimétrico & Aparición & Aromáticos C-H \\
\hline 2840 & Vibración Estiramiento Asimétrico $\mathrm{C}-\mathrm{H}, \mathrm{CH}_{2}$ y $\mathrm{CH}_{3}$ & Aumento & Alcano-Alquenos benceno \\
\hline 1618 & Vibración Alargamiento $\mathrm{C}=\mathrm{O}$ & Desaparece & Ácido carboxílico \\
\hline 1598 & $\begin{array}{l}\text { Vibración Estiramiento } \mathrm{C}=\mathrm{C} \text { característica del anillo } \\
\text { aromático }\end{array}$ & Aparece & Aromáticos \\
\hline $1433-1302$ & Banda de deformación de metilo $\mathrm{CH}_{3}$ y $\mathrm{CH}_{2}$ & Disminuye & \\
\hline 1203 & Banda de vibración en el plano $=\mathrm{CH}$ de los aromáticos $=\mathrm{CH}$ & Aparece & Aromáticos \\
\hline 1098 & $\begin{array}{l}\text { Banda de vibración Alargamiento simétrico C-C, C-O, C-O, } \\
\text { Si-O-Si, Si-O-C }\end{array}$ & Se mantiene & \\
\hline 990 & $\begin{array}{l}\text { Deformación de la vibración de alargamiento C-O } \\
\text { característica de Ar-O-CH2-O-Ar }\end{array}$ & Aparece & \\
\hline $906-875-840-757-698$ & $\begin{array}{l}\text { Deformación de sustitución de anillos aromáticos fuera del } \\
\text { plano } \gamma \mathrm{CH}_{\mathrm{AR} 1}, \gamma \mathrm{CH}_{\mathrm{AR} 2}, \gamma \mathrm{CH}_{\mathrm{AR} 3}, \gamma \mathrm{CH}_{\mathrm{AR} 4}, \gamma \mathrm{CH}_{\mathrm{AR} 5} \text {. }\end{array}$ & Aparece & $\begin{array}{l}\text { Modos normales de vibración de } \\
\text { bencenos di-sustituidos }\end{array}$ \\
\hline
\end{tabular}
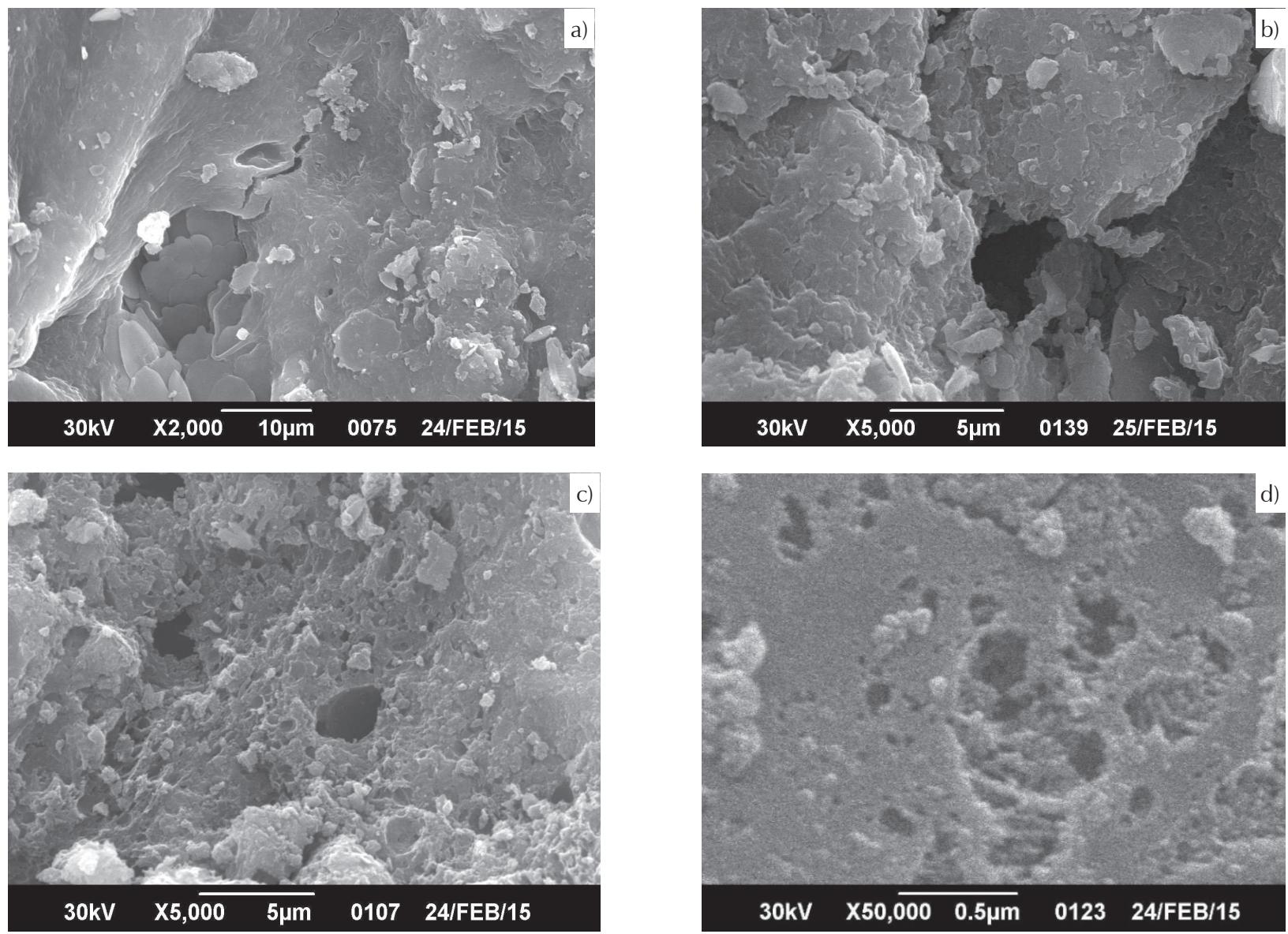

Figura 2. Fotomicrografía de la estructura externa del precursor LA y el carbón CLA mediante la técnica SEM, a) imagen LA-2000x, b) imagen LA-5000X, c) imagen CLA-5000X y d) imagen CLA- 50000X 
ción, inhibe la formación de alquitranes y cualquier otro líquido que podría obstruir los poros de la muestra. Así el movimiento de los volátiles a través de los pasajes de poros no se vería obstaculizado y los volátiles serán posteriormente liberados de la superficie de carbono durante la activación, originando cavidadades. Luego de la remoción del ácido, deja el material expandido con una estructura porosa. Esa hipótesis, gana peso con las imágenes obtenidas y presentadas en la figura 2.

Al observar la figura 2d, CLA-50000X se puede observar nítidamente una estructura superficial heterogénea en el carbón CLA, con una gran cantidad de mesoporos con tamaños que van de $0.05 \mathrm{~nm}(50 \mu \mathrm{m})$ hasta $0.01 \mathrm{~nm}(10 \mu \mathrm{m})$, en la figura $2 \mathrm{c}$ y $2 \mathrm{~d}$, respectivamente, se pueden ver algunos poros de cuerpos anchos $\mathrm{y}$ ascesos estrechos.

En la figura 3, se presentan las fotomicrografías que muestran la estructura externa de carbones preparados con diferentes porcentajes de ácido fosfórico. Se exploró la estructura morfológica de los carbones $\mathrm{C}_{20} \mathrm{y} \mathrm{C}_{30}$ con una resolución de 150X, 250X, respectivamente para cada uno.

Con estas imágenes se puede apreciar el aumento de la porosidad en el material precursor LA, cuando se trata con porcentajes mayores de $\mathrm{H}_{3} \mathrm{PO}_{4}$. En la figura $3 \mathrm{a}$ se muestra el carbón $\mathrm{C}_{20}$, donde se observa que a pesar de contar con una resolución de 150X se observan una cantidad de macroporos cuyo tamaño oscila entre $60 \mathrm{y}$ $10 \mu \mathrm{m}$, y en la figura $3 \mathrm{~b}$ del $\mathrm{C}_{30}$, con una toma a resolución mayor de 250x no se pueden observar macroporos a simple vista, lo que sí se observa cuando se aumenta la resolución a 20.000x como se muestra en la figura3b, pequeña encuadrada arriba a la derecha, Paredes (2011) y Delgadillo (2011) realizaron activaciones con $\mathrm{H}_{3} \mathrm{PO}_{4}$ sugieren que el desarrollo de porosidad estaba relacionado directamente con el aumento de la concentración del $\mathrm{H}_{3} \mathrm{PO}_{4}$.

\section{Conclusiones}

El carbón C35, que mejor porcentaje de remoción de AM presentó en la solución concentrada, $88.44 \%$ superior al resto de carbones preparados, al carbón comercial CDG60 con un $86.43 \%$.

$\mathrm{Al}$ incrementarse el porcentaje de impregnación del $\mathrm{H}_{3} \mathrm{PO}_{4}$, en los carbones preparados, aumentó su grado de porosidad confirmado por el análisis morfológico SEM, además del aumento de su capacidad de remoción de AM.

El espectro infrarrojo FTIR del CLA frente a su precursor LA, muestra la resonancia por la aparición del grupo $(\mathrm{OH})$ del fenol, el cual es bastante reactivo y deseado por sus propiedades anfóteras, lo que convierte al CLA en un potencial adsorbente de diversos compuestos.

Los lodos son el principal residuo no deseado de las plantas de tratamientos de agua residual de la industria avícola, se estudió una nueva vía para lograr la valoración de estos materiales y convertirlos en adsorbentes.

\section{Agradecimientos}

A mi señor por su ayuda durante esta investigación. Al centro de investigación del agua (CIA). A la Fundación Instituto Zuliano de Investigaciones Tecnológicas INZIT por el apoyo para realizar los análisis de esta investigación. A los compañeros de los laboratorios de la universidad Simón Bolívar por su disposición y ayuda permanente durante el transcurso de la investigación.
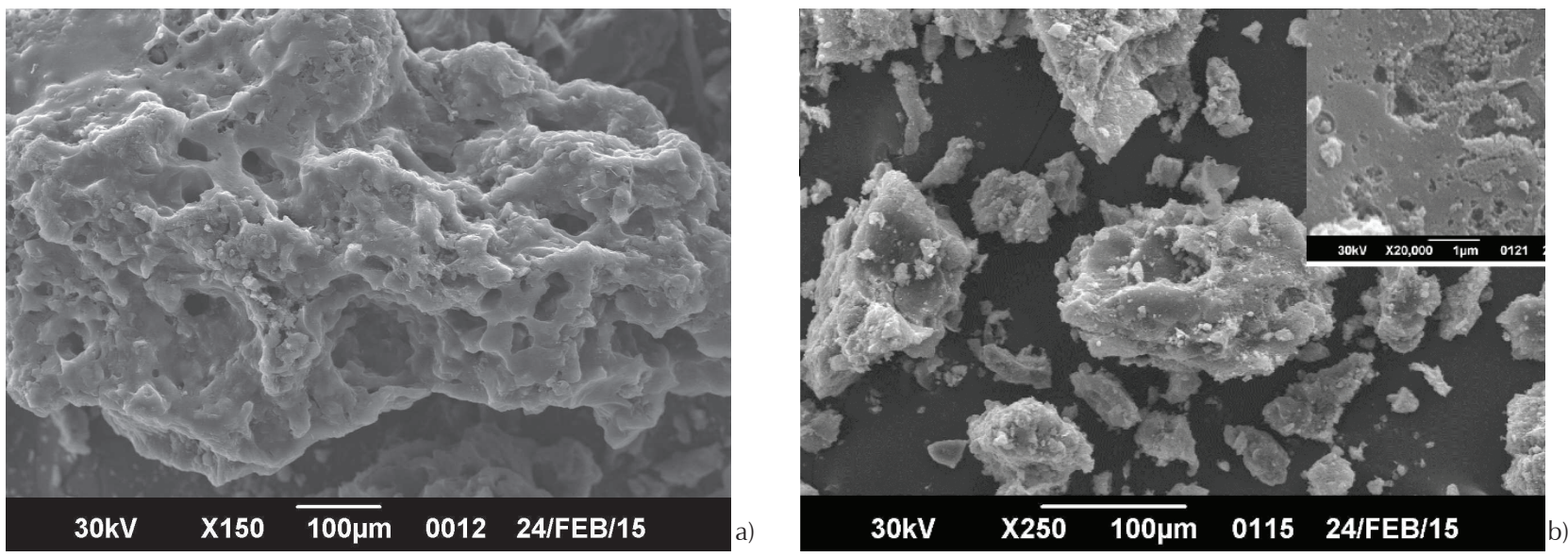

Figura 3. Fotomicrografía de la estructura externa de dos carbones $C_{20}$ y $C_{30}$ mediante la técnica SEM, a) imagen $C_{20}-150 x$, b) imagen $\mathrm{C}_{30}-250 \mathrm{X}$ 


\section{Referencias}

Bansal R.C., Donet J.B., Stoeckli F. In "Active Carbon", New York, editorial Marcel Dekker Inc., USA, 1988.

Basso M.C., Cerrella E.G., Cukierman A.L. Remocion de cadmio (II) de soluciones acuosas mediante carbón activado preparado a partir de caña. Revista Argentina. Avanc. En Energ. Renov. y Med. Amb., volumen 5, 2001: 1-6.

Caldera Y., Gutiérrez E., Luengo M., Chávez J., Ruesga L. Evaluación del sistema de tratamiento de aguas residuales de industria avícola. Revista Científica, 2010: 409-416.

Coates J. Encyclopedia of Analytical Chemistry Interpretation of Infrared Spectra, A Practical Approach, $1^{\text {ra }}$ ed., EUA, Robert A. Meyers (Editor) John Wiley \& Sons Ltd, Chichester, 2000, pp. 10815-10837.

Delgadillo-Gamboa G.A. Preparación-caracterización de carbones activados a partir de pepas de níspero de palo (Mespilus communi) y su aplicación como material adsorbente de fenol, tesis (maestria en química), Lima Perú, Pontificia Universidad Católica del Perú Facultad de Ciencias e Ingeniería, 2011, 131 p.

Giraldo L., García V., Moreno J.C. Caracterización superficial en fase gas y líquida de carbones activados. Revista de ingeniería, Universidad de los Andes, volumen 27, 2008: 7-16.

Herdenez E. Eficiencia del sistema de tratamiento de lodos generados en una planta de tratamiento de aguas residuales de una planta avícola, tesis (ingeniería química), Facultad de Ingeniería, Universidad del Zulia, Maracaibo Venezuela, 2014, 108 p.

Méndez-Novelo, R.I., Pietrogiovanna-Bronca, J.A., Santos B., Sauri-Riancho M., Giácoman G., Castillo E. Determinación de la dósis óptima de reactivo Fenton en un tratamiento de lixiviados por Fenton-adsorción. Revista internacional de contaminación ambiental, volumen 26 (número 3), agosto 2010: 211-220.

Mukherjee S., Sunil K., Amal M., Maohong F. Removal of phenols from water environment by activated carbon, bagasse ash and wood charcoal. Chemical Engineering Journal, volumen 129, octubre 2007: 133-142.
Paredes-A. Estudio de la adsorción de compuestos aromáticos mediante carbón activado preparado a partir de la cascara de castaña, tesis (licenciatura en química), Lima Perú, Pontificia Universidad Católica del Perú, Facultad de Ciencias e Ingeniería, 2011, 116 p.

Ros-Sans A. Eliminación de compuestos causantes de olores mediante adsorbentes catalizadores obtenidos a partir de lodos de depuradora, tesis (doctorado en medio ambiente), España, Universidad de Girona, 2006, 273 p.

Sarmiento C., Sánchez J., García C., Rincón Y., Benitez A., Ramirez J. Preparación de carbón activado mediante la activación química de carbón mineral. Ciencia, volumen 12 (número 1), enero-marzo 2004: 52-63.

Velázquez A., Bolaños E., Pliego Y.S. Optimización de la producción de carbón activado a partir de bambú. Revista Mexicana de Ingeniería Química, volumen 9 (número 3), diciembre 2010: 359-366.

Daouda K., Ngomo-Manga H., Baçaoui A., Yaacoubi A., KetchaMbadcam J. Optimization of activated carbons prepared by and steam activation of oil palm shells. Journal of Chemistry, volumen 2013, Article ID 654343, 10 pp., 2013.

\section{Este artículo se cita: \\ Citación estilo Chicago}

Rojas-Morales, Jorge Luis, Edixon Cristóbal Gutiérrez-González, Gilberto De Jesús Colina-Andrade. Obtención y caracterización de carbón activado obtenido de lodos de plantas de tratamiento de agua residual de una industria avícola. Ingeniería Investigación y Tecnología, XVII, 04 (2016): 453-462.

\section{Citación estilo ISO 690}

Rojas-Morales J.L., Gutiérrez-González E.C., Colina-Andrade G.J. Obtención y caracterización de carbón activado obtenido de lodos de plantas de tratamiento de agua residual de una industria avícola. Ingeniería Investigación y Tecnología, volumen XVII (número 4), octubre-diciembre 2016: 453-462. 


\section{Semblanzas de los autores}

Jorge Luis Rojas-Morales. Es magister en ingeniería ambiental (2015), ingeniero químico (1999) e investigador en el laboratorio de biotecnología del Centro de Investigaciones del agua (CIA) en la Facultad de Ingeniería de la Universidad del Zulia.

Edixon Cristóbal Gutiérrez-González. Es doctor en ingeniería ambiental, magister en ingeniería ambiental e ingeniero químico. Es profesor titular a dedicación exclusiva y jefe del laboratorio de biotecnología en el Centro de Investigaciones del agua (CIA) de la Facultad de Ingeniería de la Universidad del Zulia-LUZ. Es director del Consejo Técnico del Posgrado de la Facultad de Ingeniería de LUZ. Coordinador Académico del posgrado de la Facultad de Ingeniería de la misma universidad.

Gilberto de Jesús Colina-Andrade. Es doctor en ingeniería ambiental (2010), máster en ciencias ambientales (1998), licenciado en educación mención Biología y Química (1989). Es profesor titular a dedicación exclusiva, laboró como jefe del Departamento de Ingeniería Sanitaria y Ambiental (DISA) de la Universidad del Zulia y fue miembro de la Comisión Especial de Ambiente de la Universidad del Zulia, así como secretario del Consejo Técnico de la División de Investigación de la Facultad de Ingeniería de LUZ. Es miembro del Comité Editorial Externo de la Revista Hipoocampus de la Universidad Laica Eloy Alfaro de Manabí, Manta, Ecuador. Obtuvo la órden al mérito académico: Dr. Jesús Enrique Lossada: PRIMERA CLASE por la Universidad del Zulia (2012) y el reconocimiento como investigador nivel B en el Programa de Estímulo a la Innovación e Investigación (PEII), (2013). 